\title{
Sgk-1 is a Positive Regulator of Constitutive Albumin Uptake in Renal Proximal Tubule Cells
}

\author{
Deanne H. Hryciwa, ${ }^{a}$ Wade A. Kruger ${ }^{c}$ Jessica F. Briffa ${ }^{a} \quad$ Craig Slattery $^{d}$ \\ Adelyn Bolithone Aven Lee ${ }^{f}$ Philip Poronnik ${ }^{c}$
}

aBiomedical and Lifestyle Diseases Unit, School of Biomedical and Health Sciences, Victoria University, St Albans, Melbourne, VIC; ${ }^{b}$ Department of Physiology, The University of Melbourne, Parkville, Melbourne, VIC; 'Health Innovations Research Institute, School of Medical Sciences, RMIT University,

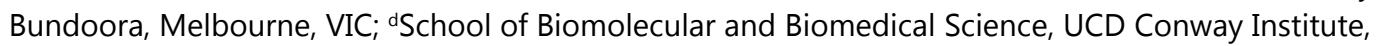
University College Dublin, Dublin; eSchool of Biomedical Sciences, The University of Queensland, Brisbane; fUniversity of Queensland Centre for Clinical Research (UQCCR), Herston, Brisbane, Queensland

\section{Key Words}

Proximal tubule • Albumin • Endocytosis • Sgk-1 • NHE3 • NHERF2

\begin{abstract}
Background/Aims: Receptor-mediated endocytosis of albumin by the renal proximal tubule requires a number of proteins including megalin/cubilin, sodium/hydrogen exchanger isoform 3 (NHE3) and ClC-5, as well as the PSD-95/Dlg/Zo-1 (PDZ) scaffold sodium/hydrogen exchanger regulatory factor 2 (NHERF2). Despite members from the AGC kinase family, v-Akt Murine Thymoma Viral Oncogene (Akt or Protein Kinase B) and Serum/Glucocorticoid regulated Kinase 1 (Sgk-1) regulating a number of essential proteins in the albumin handling pathway, their role in uptake is largely unknown. Methods: Opossum kidney (OK) cells were exposed to Texas-Red albumin, in the presence of silencing constructs against Sgk-1, Akt and NHERF2, in addition to the NHE3 inhibitor 5 -( $N$-ethyl- $N$-isopropyl)-amiloride (EIPA) and NHE3 activator dexamethasone. Target protein was also measured by Western blot analysis in OK cells following exposure to dexamethasone and albumin. Results: Silencing Sgk-1 or overexpression of a dominant negative mutant (DN-Sgk-1) led to a significant reduction of albumin endocytosis compared to control. Conversely, over-expression of wildtype (WT) or constitutively active (CA) Sgk-1 significantly increased uptake. Previous reports have shown Sgk-1 can activate NHE3 through an interaction mediated by NHERF2. We found that silencing both Sgk-1 and NHERF2 demonstrated no additive effect on uptake, suggesting signaling via similar endpoints. Treatment with dexamethasone increased Sgk-1 protein levels and increased
\end{abstract}


albumin endocytosis in OK cells. Interestingly, silencing Akt also lead to a reduction in albumin endocytosis, however in cells silenced for both Sgk-1 and Akt, the additive change in albumin uptake demonstrated that these proteins may act via separate pathways. Conclusions: We have characterized a Sgk-dependent pathway that regulates albumin uptake in the proximal tubule which also includes NHE3 and NHERF2. These data provide further insights into this essential tubular process.

Copyright $@ 2012$ S. Karger AG, Basel

\section{Introduction}

The renal proximal tubule is responsible for the reabsorption of water, $\mathrm{Na}^{+}$, glucose, amino acids and proteins from the glomerular filtrate [1]. One of the key serum proteins absorbed from the filtrate is albumin. The receptor mediated endocytosis of filtered albumin by the proximal tubule is a highly efficient process, such that $<30 \mathrm{mg}$ of albumin/day is normally excreted in the urine [2]. Excessive excretion of albumin in the urine, or albuminuria, is known to result from either increased glomerular filtration or disruption of uptake in the proximal tubule cells [3]. Albuminuria is the hallmark of renal dysfunction and is associated with the development of tubulointerstitial inflammation and fibrosis, ultimately progressing to renal failure [4].

Albumin uptake is mediated by the megalin/cubilin scavenger receptor complex that binds to the ligand at the luminal surface of the proximal tubule epithelium [5]. A recent study using a transgenic model indicate that cubilin is the essential protein that mediates albumin uptake [6]. Once internalized, albumin is then degraded in the lysosomes to its constituent amino acids that are returned to the blood $[2,5,7]$. The endocytic process requires not only the presence of the receptor complex, but has also been shown to depend on additional membrane transport proteins including the $\mathrm{Cl}^{-}$channel ClC-5, NHE3 and the v-type $\mathrm{H}^{+}-$ ATPase $[8,9]$. Importantly, the cell surface availability of any of these proteins appears to be a rate-limiting step in the endocytic process. This is a constitutive, high capacity and dynamic function of the proximal tubule that is subject to complex regulation by a number of accessory and scaffold proteins, including PDZ scaffolds (e.g. NHERF1 and NHERF2) [2, 10-13] and accessory proteins such as regulatory kinases; namely Protein Kinase C (PKC), Protein Kinase A (PKA) and Akt [14-16]. In the proximal tubule epithelium, NHE3 has two main functions, one in supporting $\mathrm{Na}^{+}$reabsorption and the other in facilitating albumin uptake, with these functions performed in separate membrane domains $[17,18]$. During the endocytosis of albumin, it appears that NHE3 also plays two roles, one as a $\mathrm{Na}^{+}-\mathrm{H}^{+}$exchanger and the other a structural role via interactions of the cytosolic tail with proteins such as megalin [19]. NHE3 itself is regulated by a number of kinases, including Akt (Akt2) and Sgk-1 [20-22]. Sgk-1 can directly phosphorylate NHE3 in vitro [23], however, glucocorticoid stimulation of NHE3 by Sgk-1 is greatly enhanced by the presence of the PDZ scaffold NHERF2 [20]. In this case, NHERF 2 anchors NHE3 and Sgk-1 in close proximity at the plasma membrane [20]. The relationship between Sgk-1 and NHE3 is further highlighted in experiments where overexpression of Sgk-1 increases NHE3 mRNA in proximal tubule cells [24], while silencing Sgk-1 decreases the activity of NHE3 [25].

Previous studies have described a role for Akt/PKB during the initial stages of albumin endocytosis involving an interaction with the megalin/cubilin complex [26]. These studies used cell-culture models to show at "physiological" concentrations of albumin, megalin/ cubilin at the cell membrane associated with Akt, in a manner that was not dependent on phosphorylation or activation of Akt [26]. In contrast, exposure to "pathophysiological" concentrations of albumin resulted in apoptosis with a reduced cell surface expression of Akt and megalin [26]. This highlights that alterations in normal signaling pathways involved in albumin uptake may play significant roles in the progression of tubulointersitial complications in renal disease [27]. Sgk-1 belongs to the AGC (cAMP-dependent protein kinase/protein 
Hryciw/Kruger/Briffa et al.: Sgk-1 Regulates Albumin Endocytosis

kinase G/protein kinase C) family of protein kinases [28, 29] and also interacts with NHE3 and NHERF2 [20] as well as Nedd4-2 [30]; all proteins implicated in albumin uptake. The current study was therefore undertaken to determine a role for Sgk-1 in albumin uptake by a cell culture model of the proximal tubule.

\section{Materials and Methods}

\section{Materials and Antibodies}

Antibodies were commercially obtained; anti-Akt (Cell Signaling, Danvers, USA), anti-Sgk-1 (Millipore, Billerica, USA) and anti- $\beta$-actin (Sigma Aldrich, Missouri, USA). Secondary antibodies conjugated to horseradish peroxidase were from Pierce (Pierce Biotechnology Inc, Illinois, USA,). Texas Red (TR)albumin was obtained from Molecular Probes (Invitrogen, Groningen, Netherlands). Inhibitor compounds; 5 -( $N$-ethyl- $N$-isopropyl)-amiloride (EIPA) were from Sigma and Akt inhibitor I was purchased from Invitrogen. Commercially available siRNA for Sgk (Sgk Validated Stealth ${ }^{\mathrm{TM}}$ RNAi Duplex 2) Invitrogen, and Akt (SignalSilence ${ }^{\circledR}$ Akt siRNA I: Cell Signaling) with their respective control plasmids. All other reagents were of the highest available purity from commercial sources.

\section{Cell Culture}

The opossum kidney (OK) cell line was maintained in a 1:1 mix of Dulbeccos modified Eagles medium with $2 \mathrm{mM} \mathrm{L-glutamine}$ and Ham's-F12 (DMEM/F12, Invitrogen) containing $100 \mathrm{U} / \mathrm{ml}$ penicillin/100 g/ $\mathrm{ml}$ streptomycin (Invitrogen). Media was supplemented with 10\% fetal bovine serum (Invitrogen) and cells were incubated at $37^{\circ} \mathrm{C}$ in $5 \% \mathrm{CO}_{2}$. For experimental protocols, OK cells were seeded and grown to confluence (approximately 5 days). Two days prior to experimentation, cells were incubated in serum-free DMEM/F12 with $5 \mathrm{mM}$ glucose (minus media).

\section{Transfections and Plasmid DNA}

OK cells were transfected with the specific plasmids described below using Lipofectamine 2000 (Invitrogen), following the manufacturers protocol. Cells were allowed to reach confluence (5 days) and then incubated with minus media for 48 hours. The plasmids used for transfection were wild-type (WT) Sgk-1, constitutively active (CA)-Sgk-1 and a dominant-negative Sgk-1 mutant (K127Q:DN-Sgk-1 [31]). Silencing construct for Sgk-1, Akt or control plasmids described above, and silencing construct against NHERF2 has been previously characterized [11,32].

\section{Albumin uptake}

Standard albumin uptake methods were used as previously described [33-35]. Where required, cells were treated with EIPA ( $50 \mu \mathrm{M}$ for 30 mins) or Akt inhibitor I ( $10 \mu \mathrm{M}$ for 1 hour), dexamethasone ( $1 \mu \mathrm{M}$ for 1 hour [23]). To determine the level of albumin uptake, cells were exposed to $50 \mu \mathrm{g} / \mathrm{ml}$ of albumin conjugated to Texas Red (TR-albumin: Molecular Probes) under the different treatments for 120 mins [34]. Non-specific fluid phase uptake was determined by exposing cells to albumin for $1 \mathrm{~min}$. At the end of the uptake period, cells were washed in HEPES buffer, $\mathrm{pH} 6$ at $4^{\circ} \mathrm{C}$, and then lysed in MOPS buffer $(20 \mathrm{mM}$ MOPS with $0.1 \%$ triton X-100). The TR-albumin fluorescence was determined using a BMG Fluostar optima (BMG technology, Offenburg, Germany) using a 590nm excitation and 620-10 emission filter set (BMG). TR-albumin uptake was standardized to total cellular protein and the amount of fluorescence per $\mu \mathrm{g}$ of cellular protein was adjusted for background and fluid phase uptake.

\section{Membrane fractionation of OK cells}

Confluent monolayers of OK cells were incubated in minus media for 48 hours then treated with low physiological concentration of albumin $(50 \mu \mathrm{g} / \mathrm{ml})$ for 2 hours. Cells were harvested and nuclei removed by centrifugation for $10 \mathrm{~min}$ at $1,000 \times g$ at $4^{\circ} \mathrm{C}$. The membrane and cytosol fractions were obtained by centrifugation at $100,000 \times \mathrm{g}$ for $1 \mathrm{~h}$ at $4^{\circ} \mathrm{C}$. The pellet was resuspended in lysis buffer ( $50 \mathrm{mM}$ Tris- $\mathrm{HCl}$ pH 7.5, $150 \mathrm{mM} \mathrm{NaCl}, 1 \%$ triton X-100 and Complete Protease inhibitors (Roche)). $50 \mu \mathrm{g}$ aliquots of the samples were added to Laemmli gel sample buffer and separated on a 5\% SDS-PAGE gel before transfer to nitrocellulose membranes. Western blot was performed using SGK antibody and the blots detected using 
Hryciw/Kruger/Briffa et al.: Sgk-1 Regulates Albumin Endocytosis

secondary antibodies conjugated to horse radish peroxidase and the SuperSignal West Pico Substrate (Pierce).

\section{Western Blot}

After treatment, cells were homogenised in the presence of ice-cold lysis buffer $(20 \mathrm{mM}$ Tris $\cdot \mathrm{HCl}, 150$ $\mathrm{mM} \mathrm{NaCl}, 1 \%$ Triton X-100, and complete mini protease inhibitor cocktail (Roche diagnostics, Penzberg, Germany). The lysate was placed on ice for $20 \mathrm{~min}$ and then centrifuged at $14,000 \mathrm{xg}$ for $10 \mathrm{~min}$ at $4^{\circ} \mathrm{C}$ to precipitate any cell debris. Protein concentration of the supernatant was measured with a BCA protein assay kit (Pierce Biotechnology Inc, Illinois, USA). Equal protein lysates were resolved on 10\% PAGE gels and transferred to nitrocellulose membranes. For protein detection, membranes were probed with the respective antibodies.

\section{Quantification of Results and Statistical Analysis}

Densitometric analysis of the Western blot data was performed using Fujifilm ScienceLab 99 Image Gauge (version 3.3). Statistical analyses of these data were performed using either a two-tailed Student's paired T-test or ANOVA where appropriate with a $\mathrm{P}$ of $<0.05$ considered significant.

\section{Results}

\section{Sgk-1 and albumin uptake}

The OK cell line is a widely accepted model of receptor-mediated albumin endocytosis by the proximal tubule $[11,16,35,36]$. We first investigated a role for Sgk-1 in albumin endocytosis by OK cells using RNA silencing and functionally modified Sgk-1 constructs. The efficacy of the silencing constructs in OK cells was first confirmed. Cells were transfected with iRNA against Sgk-1 and Western blots for Sgk-1 were then performed. In OK cells treated with iRNA against Sgk-1, the level of endogenous Sgk-1 protein was significantly reduced to $11 \pm 10 \%$ of control levels ( $n=3 ;{ }^{*} \mathrm{P}<0.01$; Fig. $1 \mathrm{~A}$ and Fig. $\left.1 \mathrm{~B}\right)$. We then determined the effect of silencing Sgk-1 on albumin uptake and found that knockdown of Sgk-1 resulted in a pronounced decrease in albumin uptake compared to control $\left(54 \pm 10 \% ; \mathrm{n}=3\right.$; ${ }^{*} \mathrm{P}<0.05$; Fig. 2A). Similarly, overexpression of a dominant negative DN-Sgk-1 caused a smaller but still significant reduction in albumin uptake $\left(81 \pm 3 \%\right.$ of control; $n=3 ;{ }^{*} \mathrm{P}<0.05$; Fig. $\left.2 \mathrm{~A}\right)$. In contrast, overexpression of WT-Sgk-1 or CA-Sgk-1 caused a pronounced increase in albumin uptake $\left(156 \pm 8 \%\right.$ and $150 \pm 10 \%$, respectively; $n=3$; ${ }^{*}<<0.05$; Fig. $\left.2 B\right)$.

It is well established that the presence and activity of NHE3 at the cell membrane is required for albumin endocytosis [37, 38] and that NHE3 is regulated by Sgk-1 [23, 31]. We therefore investigated whether the effect of silencing Sgk-1 on albumin uptake was due to inhibition of NHE3. Albumin uptake experiments were performed in control cells and cells silenced for Sgk-1. In cells treated with control iRNA, inhibition of NHE3 with EIPA (50 $\mu \mathrm{M})$ significantly reduced uptake compared to untreated control $\left(70 \pm 1 \% ; \mathrm{n}=3\right.$; ${ }^{*} \mathrm{P}<0.05$; Fig. 3A), a result consistent with the literature. In cells silenced for Sgk-1, albumin uptake was reduced to $60 \pm 5 \%\left(\mathrm{n}=6\right.$; ${ }^{*} \mathrm{P}<0.05$; compared to control: Fig. $\left.3 \mathrm{~A}\right)$ and importantly, inhibition of NHE3 with EIPA in cells silenced for Sgk-1 further reduced uptake $(28 \pm 6 \%$; $\mathrm{n}=6$; ${ }^{*} \mathrm{P}<0.05$; compared to EIPA alone: Fig. 3A). This supports our previous finding that there are two separate NHE3 pools in proximal tubule cells [39].

NHERF2 has been shown to mediate the in vivo interaction between NHE3 and Sgk-1 [20] and we have also shown that silencing of NHERF2 reduces albumin uptake in OK cells [11]. We next investigated if the effect of Sgk-1 on albumin uptake depended on NHERF2 as a scaffold. TR-albumin uptake was measured in cells in which Sgk-1 and NHERF2 were silenced. The effect of silencing NHERF2 reduced TR-albumin uptake as previously reported by our group [11]. The magnitude of this reduction was of a similar magnitude to that observed when Sgk-1 was silenced $\left(68 \pm 5 \%\right.$ and $59 \pm 9 \%$ respectively; $\mathrm{n}=3$; ${ }^{*} \mathrm{P}<0.05$, compared to control: Fig. 3B). Importantly, when both Sgk-1 and NHERF2 were silenced 


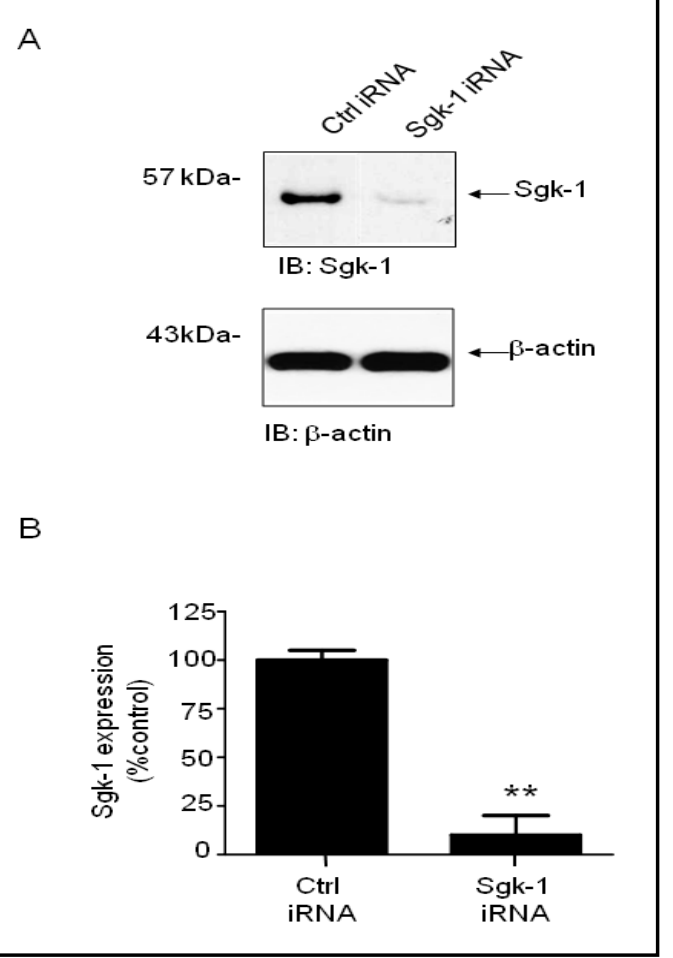

Fig. 1. Sgk-1 siRNA significantly reduces endogenous Sgk-1 in OK cells. (A) Representative Western blots showing the effect of silencing on endogenous Sgk1 levels in OK cells by transfection with siRNA. (B) Sgk-1 siRNA caused a highly significant reduction in endogenous protein $(11 \pm 10 \%)$ compared to siRNA control transfection. Values are an average of three independent experiments and are normalized to $\beta$-actin control. All data are presented as Mean \pm SEM of 3 independent experiments; *indicates statistically different to control: $\mathrm{P}<0.05$.
A

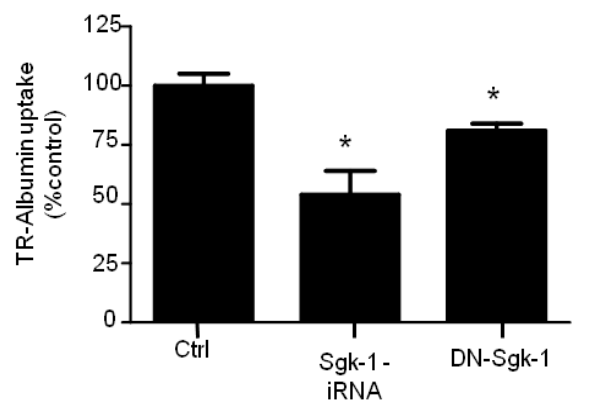

B

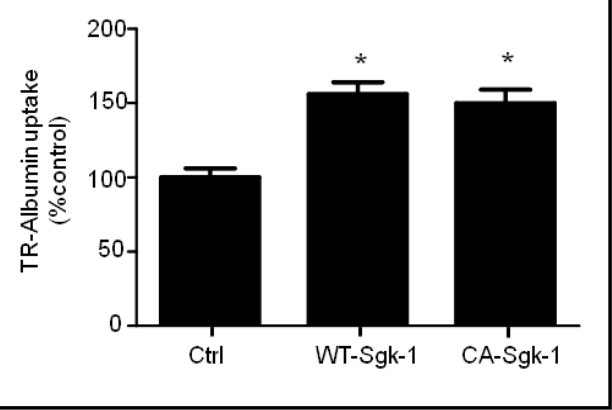

Fig. 2. Alteration of Sgk-1 expression and activity significantly alters albumin endocytosis. (A) Silencing Sgk-1 significantly decreases albumin endocytosis compared to control iRNA transfected cells (54 $\pm 10 \%)$, an effect similar to that observed in cells overexpressing a dominant negative Sgk1 (DN-Sgk-1) compared to control (81 $\pm 3 \%$ ). (B) Overexpression of wildtype (WT-Sgk-1) or constitutively active Sgk (CA-Sgk-1) significantly increases albumin endocytosis compared to control (156 $\pm 8 \%$ and $150 \pm 10 \%$, respectively). All data are presented as mean \pm SEM of 3 independent experiments; *indicates statistically different to control: $* \mathrm{P}<0.05$.

in the same cells, the extent of inhibition of TR-albumin uptake was not significantly different compared to cells in which only one of the proteins was silenced $(51 \pm 7 \% ; n=3$; ${ }^{*} \mathrm{P}<0.05$, compared to control: Fig. 3B). These data strengthen the hypothesis that Sgk- 1 and NHERF2 are acting via a common mechanism in the regulation of albumin endocytosis. We also treated the Sgk-1/NHERF2 silenced cells with EIPA and also observed no significant reduction in TR-albumin uptake compared to cells where Sgk-1 and NHERF2 were silenced ( $46 \pm 3 \% ; n=3 ;{ }^{*} P<0.05$, compared to control: Fig. $\left.3 \mathrm{~B}\right)$. These results are consistent with a model in which the Sgk-1 regulation of albumin endocytosis is due to a NHERF2 scaffolded interaction with NHE3. When comparing cells treated with EIPA alone to cells silenced for Sgk- 1 and NHERF2 and treated with EIPA there was a significant difference ${ }^{* *} \mathrm{P}<0.05, \mathrm{n}=4$, Fig. 3B), indicative of two active pools of NHE3 in proximal tubule cells [39].

It is known phosphorylation of NHE3 by Sgk-1 initiates the translocation of NHE3 to the cell surface [31]. Further, dexamethasone activates Sgk-1 and also upregulates NHE3 activity 
Fig. 3. Sgk-1 regulates uptake via a mechanism containing NHE3 and NHERF2. (A) In control iRNA cells treatment with EIPA $(1 \mu \mathrm{M})$ caused a significant decrease $(61 \pm 4 \%, n=6)$ in albumin uptake. However in cell silenced for Sgk-1 there was no additive effect of further treatment with EIPA observed in the reduction of albumin uptake. (B) In cells silenced for either Sgk-1 or NHERF2, albumin endocytosis was significantly reduced compared to control ( $67 \pm 5 \%$ and $60 \pm 9 \%$ respectively). In cells silenced for both Sgk-1 and NHERF2 uptake was also significantly reduced compared to control (52 $\pm 8 \%$ ), however this was not significantly different to cells silenced for Sgk-1 or NHERF2 alone. In cells silenced for Sgk-1 and NHERF2 and treated with EIPA, there was a reduction in albumin uptake compared to cells treated with EIPA alone. All data are presented as mean \pm SEM of 3 independent experiments unless indicated; *indicates statistically different to control ** indicates statistically significant to EIPA alone: ${ }^{*} \mathrm{P}<0.05,{ }^{* *} \mathrm{P}<0.05$.
A

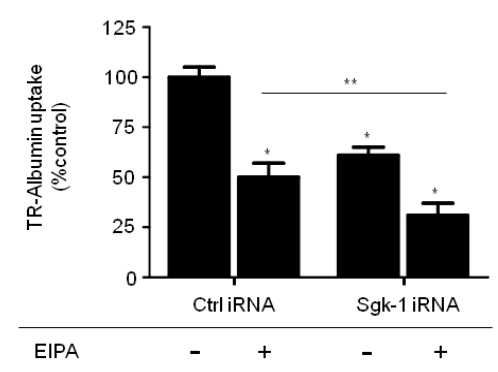

B

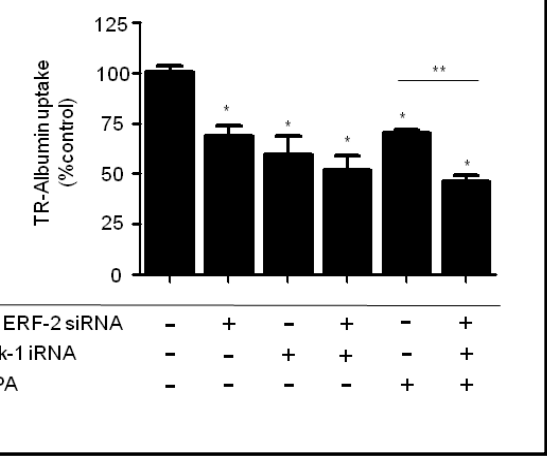

[23] thus we hypothesized that dexamethasone treatment should increase albumin uptake. In these experiments, exposure of OK cells to dexamethasone ( $1 \mu \mathrm{M}$ for 2 hours) resulted in a significant increase in Sgk-1 protein in the OK cells $(175 \pm 5 \%, * P<0.05, n=4$, Fig. 4A). TR-albumin uptake also increased in cells treated with dexamethasone compared to control $(122 \pm 5 \%, * \mathrm{P}<0.05, \mathrm{n}=4$, Fig. 4B). In cells exposed to albumin, and fractionated, in the cell membrane pool there was a significant increase in Sgk-1 in the whole cell and membrane fractions compared to cells not exposed to albumin $(112 \pm 5 \%$ and $110 \pm 4 \%$, respectively * $\mathrm{P}<0.05, \mathrm{n}=4$, Fig. 4C and 4D).

\section{Akt is required for albumin uptake}

Given the potential overlap between Sgk-1 and Akt signaling pathways, we used a combination of gene silencing and pharmacological inhibition to establish if the two proteins were acting via a common pathway to regulate albumin uptake. We first used two concentrations of siRNA Akt to determine the effects on whole cell protein expression and to further investigate if this had an effect on TR-albumin uptake. Western blot analysis showed a concentration dependent reduction in Akt protein $(25 \mathrm{nM}: 77 \pm 5 \%, * \mathrm{P}<0.05$ and $50 \mathrm{nM}$ : $63 \pm 5 \%,{ }^{*} \mathrm{P}<0.01$, Figs. $5 \mathrm{~A}$ and $5 \mathrm{~B}$ ). Importantly, this was accompanied by a significant reduction in TR-albumin uptake, compared to control (Akt siRNA: 25nM: $61 \pm 4 \%$, 50nM: 58 $\pm 7 \% ; \mathrm{n}=3{ }^{*} \mathrm{P}<0.05$, Fig. 5C). Further, pharmacological blockade of Akt with Akt inhibitor 1 also caused a significant decrease in TR-albumin uptake similar to that observed with siRNA ( $58 \pm 10 \% ; n=4 ;{ }^{*}<<0.05$; compared to control: Fig. 5 C). These data clearly show that Akt is a regulator of constitutive albumin uptake in $\mathrm{OK}$ cells.

\section{Sgk-1 and Akt act on separate pathways to regulate albumin uptake}

Sgk-1 and Akt can act on the same phosphorylation consensus sequences sites on target proteins and thus can act on the same pathways [40]. Further, both proteins are known to alter trafficking and activity of NHE3 $[31,41]$. We therefore silenced Sgk-1 and treated the cells with Akt inhibitor I. Compared to cells in which Sgk-1 was silenced, treatment with the Akt inhibitor caused a further significant reduction in TR-albumin uptake (Sgk-1 iRNA alone: $50 \pm 7 \%$ and Sgk-1 iRNA and Akt inhibitor $31 \pm 6 \%$, respectively, $\mathrm{n}=3,{ }^{* *} \mathrm{P}<0.05$, 


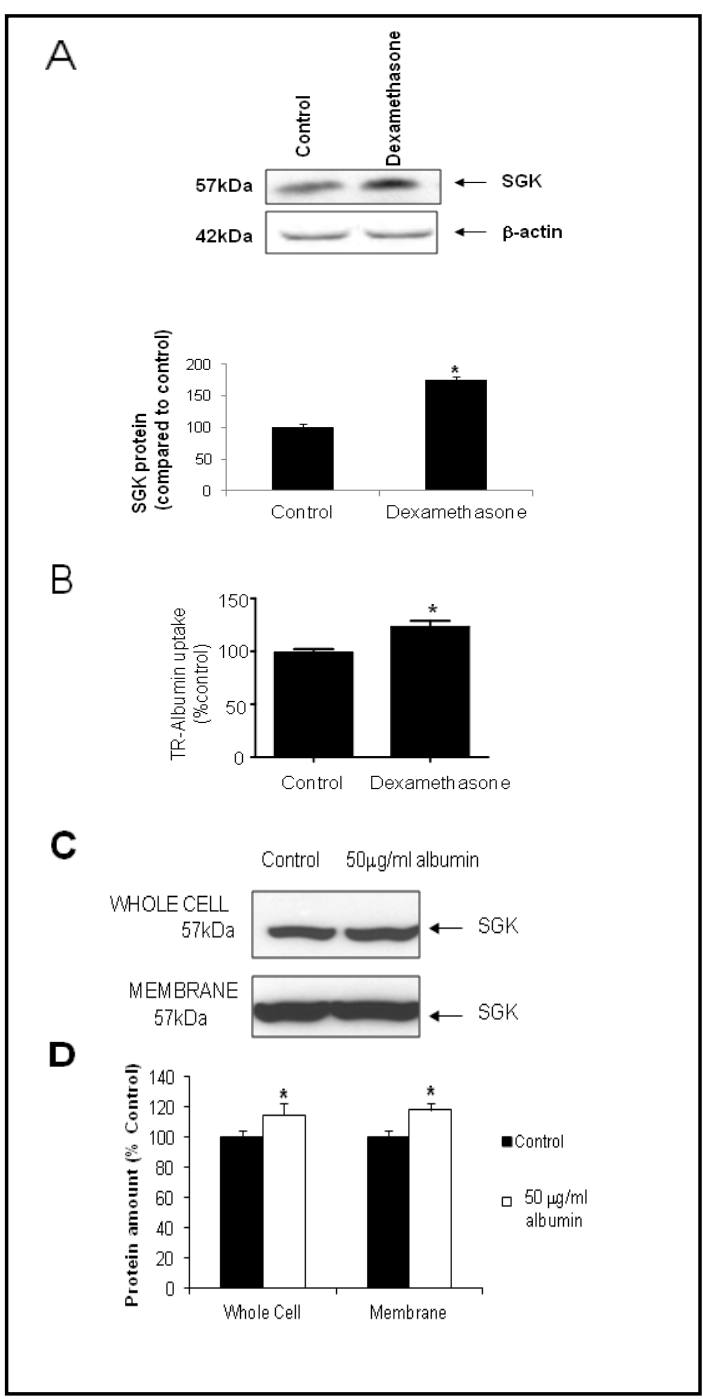

Fig. 4. Activation of $\mathrm{Sgk}$ with dexamethasone significantly increases albumin uptake. (A) Western blot analysis of OK cells treated with $1 \mu \mathrm{M}$ dexamethasone (a known activator of Sgk-1) leads to a significant (175 $\pm 5 \%$ ) increase in Sgk-1 protein. (B) In addition, treatment with dexamethasone significantly $(122 \pm 5 \%)$ increases in albumin uptake in OK cells compared to control. (C) OK cells treated with a physiological $(50 \mu \mathrm{g} / \mathrm{ml})$ concentration of albumin demonstrated an increase in whole cell and cell membrane levels of Sgk-1. (D) Densitometry analysis of the Western blot data indicated a significant increase in Sgk-1 in the membrane and whole cell lysate in response to albumin. All data are presented as mean \pm SEM of at least 3 independent experiments; *indicates statistically different to control: ${ }^{*} \mathrm{P}<0.05$.

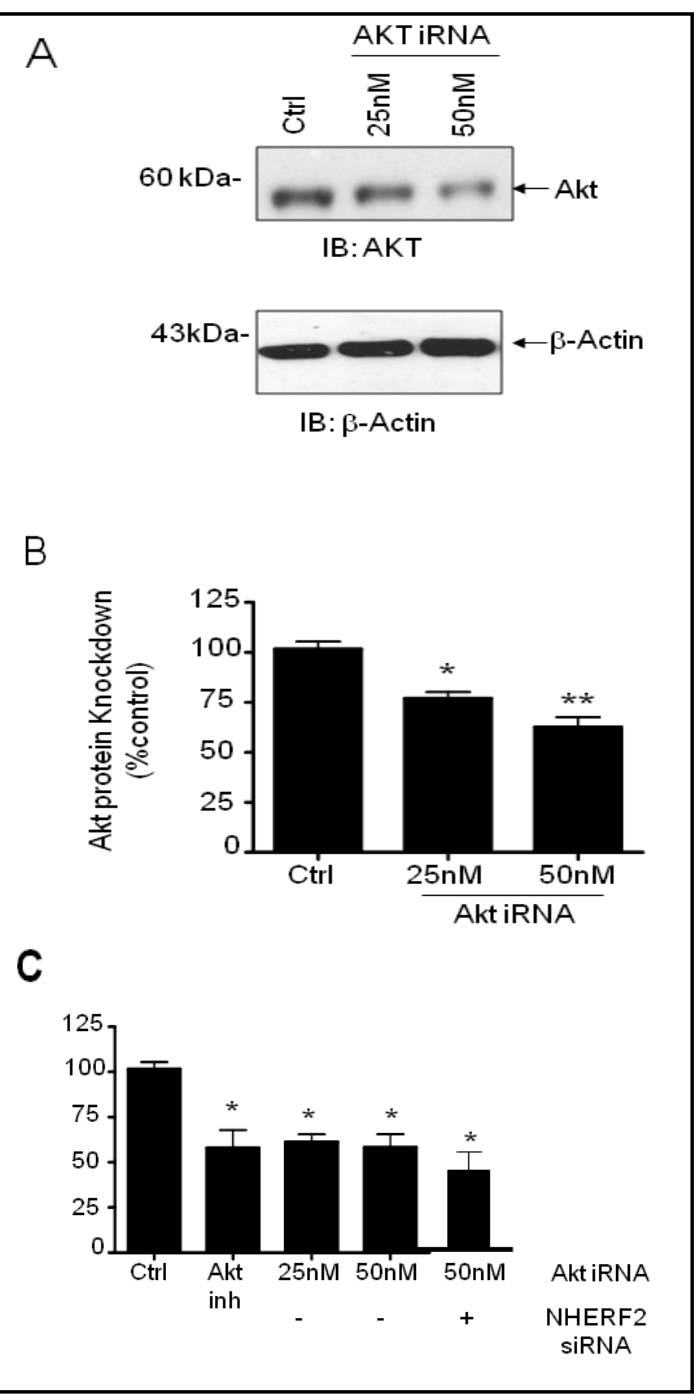

Fig. 5. Akt regulates constitutive albumin endocytosis. (A) Representative Western blot showing the change in endogenous expression of Akt following transfection with increasing concentrations of Akt siRNA. (B) Treatment of OK cells with Akt siRNAs causes a significant decrease in Akt protein levels compared to untreated cells (25nm: $77 \pm 5 \%$, and 50nM: $63 \pm 5 \%$ ).(C) Treatment of OK cells with Akt inhibitor I or Akt siRNA causes a significant decrease in albumin endocytosis compared to untreated cells (58 $\pm 10 \%$; and $25 \mathrm{~nm}$ : $61 \pm 4 \%, 50 \mathrm{nM}$ : $58 \pm 7 \%$ respectively). All data are presented as mean \pm SEM of at least 3 independent experiments; *indicates statistically different to control: ${ }^{*} \mathrm{P}<0.05$.

Fig. 6). This important result suggests that Akt and Sgk-1 regulate albumin endocytosis in proximal tubule cells by distinct pathways. 
Fig. 6. Sgk-1 and Akt regulate albumin endocytosis via separate pathways. In control iRNA transfected cells, Akt inhibitor I caused a significant decrease in albumin endocytosis compared to untreated cells, and the Sgk-1 iRNA also showed the same characteristic reduction in uptake as observed in prior experiments. When both treatments were applied at the same time there was a significant additive affect observed causing further significant reduction in uptake $(31 \pm 6 \%)$. All data are presented as mean \pm SEM of at least 3 independent experiments; *indicates statistically different to control: ${ }^{*} \mathrm{P}<0.05 ;{ }^{* *}$ indicates statistically different to Sgk-1 iRNA: ${ }^{* *} \mathrm{P}<0.05$.

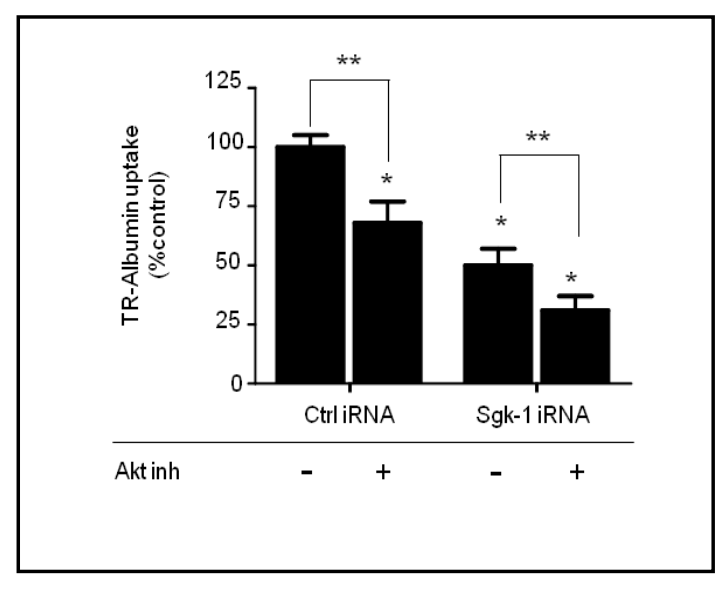

\section{Discussion}

In this study we describe a novel role for Sgk-1 in the endocytic uptake of albumin in proximal tubule epithelial cells, a role that is likely to be different to that reported for Akt. By manipulating the endogenous proteins in OK cells, we were able to show that 1 ) in response to albumin, Sgk-1 is translocated to the cell membrane, 2) Sgk-1 is increased in response to dexamethasone and 3) stimulation of NHE3 by dexamethasone acts via a NHERF2 pathway. Previous research in OK proximal tubule cells has clearly demonstrated that NHE3 activity is regulated by via NHERF2 and Sgk-1, in a dexamethasone manner [20,31]. To further add to this knowledge we have demonstrated that dexamethasone and albumin increase the availability of Sgk-1 in the proximal tubule cell, and this pathway regulates albumin endocytosis. The Sgk-1 regulated pathway is dependent on NHERF2. We have previously shown using electron microscopy that in our OK cells, endogenous NHERF2 is predominantly associated with subapical endosomes at the intervillar clefts [11], the subcellular domain in which albumin uptake occurs. Conversely, other studies using a different OK cell clone in which NHERF2 is not endogenously expressed, and therefore rely on overexpression strategies (e.g. [20]).

There have been many studies on the mechanisms that regulate albumin uptake in renal proximal tubules. A striking feature is that no individual pharmacological treatment (with the exception of cytoskeletal disruption) causes more than $\sim 50 \%$ inhibition, indicating that this constitutive process is under the control of multiple pathways. Our initial experiments clearly revealed a significant role for endogenous Sgk-1 in regulating constitutive albumin uptake. Silencing Sgk-1 or inhibiting its kinase activity decreased albumin uptake, while increasing the levels of Sgk-1 increased albumin uptake. NHE3 mediated acidification appears to play an important role in the endocytic pathway and pharmacological inhibition is reported to delay the fusion of the newly formed endosome and cause a pronounced inhibition of albumin uptake [37]. Consequently, it follows that increased NHE3 activity could support increased albumin uptake. Thus the increase in albumin uptake we observed with dexamethasone a treatment that is well characterized to stimulate NHE3, did result in the predicted increase in albumin uptake. Of note, is that NHE3 is present in 2 pools in the proximal tubule cells [39], suggesting distinctive regulatory pathways may exist between the two pools.

NHERF2 plays a key role in scaffolding the assembly of a specific dexamethasone induced signaling complex between Sgk-1 and NHE3. We have previously shown that silencing NHERF2 decreases albumin uptake [37] and in the current study we found that there was no significant potentiation of inhibition of albumin uptake when Sgk-1 and NHERF2 were both were silenced. These data taken together present a mechanism as to why silencing NHERF2 inhibits albumin uptake. NHE3 activity is essential for a substantial component of constitutive albumin uptake. Sgk-1 regulates the activity of NHE3 and thereby the efficiency 
of albumin uptake. It is the presence of NHERF2 that maximizes the interaction between Sgk1 and NHE3 and when NHERF2 is absent, that component of the uptake of albumin is lost. The dynamic nature and regulated nature of the interactions between NHERF2 and NHE3 is highlighted in recent studies using methods such as fluorescence resonance energy transfer and photo-bleaching recovery $[20,42]$.

Sgk-1 is widely expressed in the kidney and although it is predominantly expressed in the distal nephron there is evidence to support its expression and presence in the proximal tubule, albeit at lower levels [43]. In addition, cultured proximal tubule cells (both primary and clonal) express Sgk-1 [44, 45]. The significance of this kinase can be demonstrated by the number of physiological and pathophysiological functions in which it is involved. For example, changes in the levels of Sgk-1 are observed when cells are subject to stress, such as under conditions where cell volume is altered [46], and in cells exposed to high glucose [47]. Further, Sgk-1 has been shown to have altered expression in a number of renal disease states such as diabetic nephropathy [48], glomerulonephritis and nephrotic syndrome via activation of fibrotic pathways (for review please see [49]). Specifically, in diabetic nephropathy, the levels of Sgk-1 increase in the proximal tubules [48], which may be due to exposure to high levels of glucose [24]. Sgk-1 has also been shown to regulate the tubular glucose transporter SGLT-1 [50]. In addition, overexpression of Sgk-1 has been shown to increase the production of the matrix protein fibronectin only in the presence of elevated levels of glucose [45]. Conversely, the absence of Sgk-1 can be protective as shown in studies using DOCA/high salt treated mice where glomerulosclerosis and tubulointerstitial fibrosis was blunted in Sgk-1\% mice compared to wild type controls [51]. Sgk-2 is also expressed in the proximal tubule and a recent study showed that overexpression of constitutively active Sgk-2 in OKP cells increased NHE3 activity but were unable to demonstrate any effect with Sgk-1 [43]. Unlike Sgk-2, which is not reported to interact with NHERF2 effective regulation of NHE3 by Sgk-1 requires NHERF2 [20]. The OKP cells used in the Sgk-2 study are not reported to express adequate levels of endogenous NHERF2 [43] hence the lack of effect of Sgk-1 that these investigators observed may be simply due to the absence of NHERF2.

A role for Sgk-1 in albumin endocytosis in OK cells is a novel finding but is not unexpected given that Sgk-1 not only regulates the activity NHE3 but also the ubiquitin ligase Nedd4-2 [30] that has a putative role in albumin endocytosis [36]. The regulation of albumin uptake by AGC kinases has been described before, with previous studies clearly identifying a role for Akt in angiotensin II mediated albumin uptake $[18,42]$. However, there are some differences between the data presented here, and the previous work of Caruso-Neves et al. $[14,26]$. Initially, in our experimental model opossum kidney (OK) proximal tubule cells are exposed to physiological concentrations (50 $\mathrm{g} / \mathrm{ml}$ TR-albumin) of albumin for 2 hours [11, 16, 34, $36]$. In the previous experiments [14], these authors used a different cell model, the porcine proximal tubule cell line LLC-PK1, and measured short term albumin uptake (15 mins) using $10 \mathrm{mg} / \mathrm{ml} \mathrm{FITC}$-albumin with measurement of uptake by confocal analysis. In the absence of angiotensin II, Caruso-Neves et al. [14] failed to detect a direct affect of Akt/PKB on albumin endocytosis. However, under our experimental conditions, we were able to demonstrate in OK cells that either silencing or pharmacological inhibition of Akt significantly reduced albumin uptake. Importantly, we were also able to show that the inhibitory effects of Akt and Sgk-1 inhibition were additive, indicating that the pathways by which Akt and Sgk-1 regulate constitutive albumin uptake are distinct.

It is becoming increasingly clear that renal albumin uptake is a highly dynamic process that requires careful orchestration between a variety of receptors and proteins as well as accessory proteins such as kinases and scaffolds in macromolecular complexes [9]. Such complexes are widely recognized to direct functional specificity and the efficiency of the multiple signal transduction pathways that target membrane proteins within the complex to fine tune the activity of the complex via specific and separate mechanisms as has been recently described for NHE3 $[52,53]$. This highlights the complexity in the regulation of normal renal albumin uptake and in this paper we provide the molecular basis for a role for Sgk-1 in albumin uptake that is distinct from that of Akt. The challenge for future studies is 
Hryciw/Kruger/Briffa et al.: Sgk-1 Regulates Albumin Endocytosis

to understand how the many pathways that potentially regulate constitutive albumin uptake are recruited or altered in disease.

\section{Grants}

This work was supported by grants from the National Health and Medical Research Council of Australia (P. P.), Helen McPherson Smith Trust (D.H.) and University of Queensland New Staff Research Start-Up Fund (D.H.). C.S. is funded by the Irish Research Council for Science, Engineering and Technology.

\section{References}

1 Shenolikar S, Minkoff CM, Steplock DA, Evangelista C, Liu M-Z, Weinman EJ: N-terminal PDZ domain is required for NHERF dimerization. FEBS lett 2001;489:233-236.

2 Gekle M: Renal tubule albumin transport. Ann Rev Physiol 2005;67:573-594.

-3 Ziyadeh FN, Snipes ER, Watanabe M, Alvarez RJ, Goldfarb S, Haverty TP: High glucose induces cell hypertrophy and stimulates collagen gene transcription in proximal tubule. Am J Physiol 1990;259:F704714.

-4 Remuzzi G, Bertani T: PathoPhysiol of progressive nephropathies. New Engl J Med 1998;339:1448-1456.

5 Christensen EI, Birn H: Megalin and cubilin: synergistic endocytic receptors in renal proximal tubule. Am J Physiol Renal Physiol 2001;280:F562-F573.

6 Amsellem S, Gburek J, Hamard G, Nielsen R, Willnow TE, Devuyst O, Nexo E, Verroust PJ, Christensen EI, Kozyraki R: Cubilin is essential for albumin reabsorption in the renal proximal tubule. J Am Soc Nephrol 2010;21:1859-1867.

7 Pollock CA, Poronnik P: Albumin transport and processing by the proximal tubule: Physiology and pathophysiology. Curr Opin Nephrol Hypertens 2007;16:359-364.

8 Ozdemir AM, Hopfer U, Erhard P, Monnier VM, Weiss M: Processing Advanced Glycation End ProductModified Albumin by the Renal Proximal Tubule and the Early Pathogenesis of Diabetic Nephropathy. Ann NY Acad Sci 2005;1043:625-636.

-9 Hryciw DH, Ekberg J, Pollock CA, Poronnik P: ClC-5: A chloride channel with multiple roles in renal tubular albumin uptake. Int J Biochem Cell Biol 2005;38:1036-1042.

10 Birn H, Christensen EI: Renal albumin absorption in physiology and pharmacology. Kidney Int 2006;69:440-449.

11 Hryciw DH, Ekberg J, Ferguson C, Lee A, Wang D, Parton RG, Pollock CA, Yun CC, Poronnik P: Regulation of albumin endocytosis by PSD95/Dlg/ZO-1 (PDZ) scaffolds. Interaction of $\mathrm{Na}^{+}-\mathrm{H}^{+}$exchange regulatory factor2 with ClC-5. Journal of Biological Chemistry 2006;281:16068-16077.

12 Hryciw DH, Jenkin KA, Simcocks AC, Grinfeld E, McAinch AJ, Poronnik P: The interaction between megalin and ClC-5 is scaffolded by the $\mathrm{Na}^{+}-\mathrm{H}^{+}$exchanger regulatory factor 2 (NHERF2) in proximal tubule cells. Int J Biochem Cell Biol 2012;44:815-823.

13 Slattery C, Jenkin K, Lee A, Simcocks A, McAinch A, Poronnik P, Hryciw D: $\mathrm{Na}^{+}-\mathrm{H}^{+}$exchanger regulatory factor 1 (NHERF1) PDZ scaffold binds an internal binding site in the scavenger receptor megalin. Cell Physiol Biochem 2011;27:171-178.

14 Caruso-Neves C, Kwon SH, Guggino WB: Albumin endocytosis in proximal tubule cells is modulated by angiotensin II through an AT2 receptor-mediated protein kinase B activation. Proc Natl Acad Sci 2005;102:17513-17518.

15 Gekle M, Mildenberger S, Freudinger R, Schwerdt G, Silbernagl S: Albumin endocytosis in OK cells: dependence on actin and microtubules and regulation by protein kinases. Am J Physiol 1997;272:F668F677. 
16 Hryciw DH, Pollock CA, Poronnik P: PKC $\alpha$ mediated remodelling of the actin cytoskeleton is involved in constitutive albumin uptake by proximal tubule cells. Am J Physiol Renal Physiol 2005;288:F1227-F1235.

17 Gekle M, Serrano OK, Drumm K, Mildenberger S, Freudinger R, Gassner B, Jansen HW, Christensen EI: NHE3 serves as a molecular tool for cAMP-mediated regulation of receptor-mediated endocytosis. Am J Physiol Renal Physiol 2002;283:F549-F558.

18 Gekle M, Volker K, Mildenberger S, Freudinger R, Shull GE, Wiemann M: NHE3 Na $/ \mathrm{H}^{+}$exchanger supports proximal tubular protein reabsorption in vivo. Am J Physiol Renal Physiol 2004;287:F469-473.

19 Biemesderfer D, DeGray B, Aronson PS: Active (9.6S) and inactive (21S) oligomers of NHE3 in microdomains of the renal brush border. J Biol Chem 2001;276:10161-10167.

-20 Yun CC, Chen Y, Lang F: Glucocorticoid activation of $\mathrm{Na}^{+} / \mathrm{H}^{+}$exchanger isoform 3 revisited. The roles of SGK1 and NHERF2. J Biol Chem 2002;277:7676-7683.

21 Shiue H, Musch MW, Wang Y, Chang EB, Turner JR: Akt2 phosphorylates ezrin to trigger NHE3 translocation and activation. J Biol Chem 2005;280:1688-1695.

22 Lee-Kwon W, Kawano K, Choi JW, Kim JH, Donowitz M: Lysophosphatidic acid stimulates brush border $\mathrm{Na}^{+} / \mathrm{H}^{+}$exchanger 3 (NHE3) activity by increasing its exocytosis by an NHE3 kinase A regulatory proteindependent mechanism. J Biol Chem 2003;278:16494-16501.

23 Wang D, Zhang H, Lang F, Yun CC: Acute activation of NHE3 by dexamethasone correlates with activation of SGK1 and requires a functional glucocorticoid receptor. Am J Physiol Cell Physiol 2007;292:C396-C404.

24 Saad S, Stevens VA, Wassef L, Poronnik P, Kelly DJ, Gilbert RE, Pollock CA: High glucose transactivates the EGF receptor and up-regulates serum glucocorticoid kinase in the proximal tubule. Kidney Int 2005;68:985-997.

25 Stevens VA, Saad S, Poronnik P, Fenton-Lee CA, Polhill TS, Pollock CA: The role of Sgk-1 in angiotensin II mediated sodium reabsorption in human proximal tubular cells. Nephrol Dial Transplant 2008;23:18341843.

26 Caruso-Neves C, Pinheiro AA, Cai H, Souza-Menezes J, Guggino WB: PKB and megalin determine the survival or death of renal proximal tubule cells. Proc Natl Acad Sci 2006;103:18810-18815.

27 Feliers D, Duraisamy S, Faulkner JL, Duch J, Lee AV, Abboud HE, Choudhury GG, Kasinath BS: Activation of renal signaling pathways in db/db mice with type 2 diabetes. Kidney Int 2001;60:495-504.

28 Cantrell DA: Phosphoinositide 3-kinase signalling pathways. J Cell Sci 2001;114:1439-1445.

29 Brazil DP, Hemmings BA: Tens years of PKB signaling: A hard Akt to follow. Trends Biochem Sci 2001;26:657-664.

-30 Snyder PM, Olson DR, Thomas BC: Serum and glucocorticoid-regulated kinase modulates Nedd4-2mediated inhibition of the epithelial $\mathrm{Na}^{+}$channel. J Biol Chem 2002;277:5-8.

-31 Wang D, Sun H, Lang F, Yun CC: Activation of NHE3 by dexamethasone requires phosphorylation of NHE3 at Ser663 by Sgk1. Am J Physiol Cell Physiol 2005;289:C802-C810.

32 Kruger WA, Yun CC, Monteith GR, Poronnik P: Muscarinic-induced recruitment of plasma membrane $\mathrm{Ca}^{2+}$ ATPase involves PSD-95/Dlg/Zo-1-mediated interactions. J Biol Chem 2009;284:1820-1830.

-33 Lee EM, Pollock CA, Drumm K, Berden J, Poronnik P: Effects of pathophysiological concentrations of albumin on NHE3 activity and cell proliferation in primary cultures of human proximal tubule cells. Am J Physiol Renal Physiol 2003;285:F748-F757.

34 Hryciw DH, Wang YH, Devuyst O, Pollock CA, Poronnik P, Guggino WB: Cofilin interacts with ClC-5 and regulates albumin uptake in proximal tubule cell lines. J Biol Chem 2003;278:40169-40176.

-35 Drumm K, Lee E, Stanners S, Gassner B, Gekle M, Poronnik P, Pollock CA: Albumin and glucose effects on cell growth parameters, albumin uptake and $\mathrm{Na}^{+} / \mathrm{H}^{+}$isoform 3 in OK cells. Cell Physiol Biochem 2003;13:199-206.

-36 Hryciw DH, Ekberg J, Lee A, Lensink IL, Kumar S, Guggino WB, Cook DI, Pollock CA, Poronnik P: Nedd4-2 functionally interacts with ClC-5: involvement in constitutive albumin endocytosis in proximal tubule cells. J Biol Chem 2004;279:54996-55007.

37 Gekle M, Drumm K, Mildenberger S, Freudinger R, Gassner B, Silbernagl S: Inhibition of $\mathrm{Na}^{+}-\mathrm{H}^{+}$exchange impairs receptor-mediated albumin endocytosis in renal proximal tubule-derived epithelial cells from opossum. J Physiol 1999;520:709-721.

38 Gekle M, Freudinger R, Mildenberger S: Inhibition of $\mathrm{Na}^{+}-\mathrm{H}^{+}$exchanger-3 interferes with apical receptormediated endocytosis via vesicle fusion. J Physiol 2001;531:619-629. 
39 Wang Y, Cai H, Cebotaru L, Hryciw DH, Weinman EJ, Donowitz M, Guggino SE, Guggino WB: ClC-5: role in endocytosis in the proximal tubule. Am J Physiol Renal Physiol 2005;289:F850-862.

40 Leslie NR, Biondi RM, Alessi DR: Phosphoinositide-regulated kinases and phosphoinositide phosphatases. Chem Rev 2001;101:2365-2380.

41 Lee-Kwon W, Johns DC, Cha B, Cavet M, Park J, Tsichlis P, Donowitz M: Constitutively active phosphatidylinositol 3-kinase and AKT are sufficient to stimulate the epithelial $\mathrm{Na}^{+} / \mathrm{H}^{+}$exchanger 3. J Biol Chem 2001;276:31296-31304.

42 Cha B, Kenworthy A, Murtazina R, Donowitz M: The lateral mobility of NHE3 on the apical membrane of renal epithelial OK cells is limited by the PDZ domain proteins NHERF1/2, but is dependent on an intact actin cytoskeleton as determined by FRAP. J Cell Sci 2004;117:3353-3365.

43 Pao AC, Bhargava A, Di Sole F, Quigley R, Shao X, Wang J, Thomas S, Zhang J, Shi M, Funder JW, Moe OW, Pearce D: Expression and role of serum and glucocorticoid-regulated kinase 2 in the regulation of $\mathrm{Na}^{+} / \mathrm{H}^{+}$ exchanger 3 in the mammalian kidney. Am J Physiol Renal Physiol 2010;299:F1496-F1506.

44 Saad S, Agapiou DJ, Chen XM, Stevens VA, Pollock CA: The role of Sgk-1 in the upregulation of transport proteins by PPAR- $\gamma$ agonists in human proximal tubule cells. Nephrol Dial Transplant 2009;24:1130-1141.

45 Stevens VA, Saad S, Chen XM, Pollock CA: The interdependence of EGF-R and Sgk-1 in fibronectin expression in primary kidney cortical fibroblast cells. Int J Biochem Cell Biol 2007;39:1047-1054.

46 Waldegger S, Barth P, Raber G, Lang F: Cloning and characterization of a putative human serine/threonine protein kinase transcriptionally modified during isotonic and isotonic alterations of cell volume. Proc Natl Acad Sci 1997;94:4440-4445.

47 Houtman JC, Barda-Saad M, Samelson LE: Examining multiprotein signaling complexes from all angles. FEBS J 2005;272:5426-5435.

-48 Kumar JM, Brooks DP, Olson BA, Laping NJ: Sgk, a putative serine/threonine kinase, is differentially expressed in the kidney of diabetic mice and humans. J Am Soc Nephrol 1999;10:2488-2494.

-49 Lang F, Böhmer C, Palmada M, Seebohm G, Strutz-Seebohm N, Vallon V: (Patho)physiological significance of the serum- and glucocorticoid-inducible kinase isoforms. Physiol Rev 2006;86:1151-1178.

50 Dieter M, Palmada M, Rajamanickam J, Aydin A, Busjahn A, Boehmer C, Luft FC, Lang F: Regulation of glucose transporter SGLT1 by ubiquitin ligase Nedd4-2 and kinases SGK1, SGK3, and PKB. Obes Res 2004;12:862-870.

51 Artunc F, Amann K, Nasir O, Friedrich B, Sandulache D, Jahovic N, Risler T, Vallon V, Wulff P, Kuhl D, Lang F: Blunted DOCA/high salt induced albuminuria and renal tubulointerstitial damage in gene-targeted mice lacking SGK1. J Mol Med 2006;84:737-746.

52 Zhang W, Naren AP: Bioactive phospholipids signaling influences NHE3-dependent intestinal $\mathrm{Na}^{+}$and fluid absorption: a macromolecular complex perspective. Am J Physiol Cell Physiol 2011;301:C982-C983.

53 Zhu X, Cha B, Zachos NC, Sarker R, Chakraborty M, Chen TE, Kovbasnjuk O, Donowitz M Elevated calcium acutely regulates dynamic interactions of NHERF2 and NHE3 in OK cell microvilli. J Biol Chem 2011;286:34486-34496. 